\title{
EFEITO DA APLICAÇÃO FOLIAR DE BORO E ZINCO SOBRE A PRODUÇÃO E OS TEORES DE SST E ATT DOS FRUTOS DA PEREIRA-JAPONESA E DA PINHEIRA ${ }^{1}$
}

\author{
REGINA CÉLIA FARIA SIMÃO CANESIN² \& SALATIÉR BUZETTI ${ }^{3}$
}

RESUMO- Pulverizações foliares com produtos contendo micronutrientes, dentre os quais os produtos quelatizados, são utilizadas com relativa freqüência em frutíferas, sem o embasamento científico adequado, principalmente entre os agricultores mais tecnificados. Neste contexto, o objetivo deste trabalho foi verificar o efeito da aplicação via foliar de B e Zn sobre a produção e os teores de SST e ATT dos frutos da Pereira-Japonesa e da Pinheira. O experimento foi conduzido numa área irrigada, situada no cinturão verde do município de Ilha Solteira-SP. O solo da área foi classificado como Podzólico Vermelho-Escuro. Foram utilizadas plantas de PereiraJaponesa, cultivar Okussankichi e de Pinheira. Os tratamentos utilizados foram: T1. apenas água; T2. ácido bórico; T3. sulfato de zinco; T4. T2 + T3; T5. ácido bórico + uréia + ácido cítrico + EDTA; T6. sulfato de zinco + uréia + ácido cítrico + EDTA; T7. T5 + T6; T8. ácido bórico + uréia + ácido cítrico + EDTA + molibdato de sódio + enxofre + cloreto de cálcio; T9. sulfato de zinco + ácido cítrico + EDTA + sulfato de Fe + sulfato de Mn + sulfato de Mg, e T10. T8+T9. Foram utilizadas doses de $110 \mathrm{~g} \mathrm{ha}^{-1} \mathrm{de} \mathrm{B}$ e $250 \mathrm{~g}$ ha $^{-1}$ de $\mathrm{Zn}$, em cada aplicação. O delineamento experimental adotado foi o de blocos ao acaso, com quatro repetições e, para comparação de médias, foi utilizado o teste de Tukey. Com base nos resultados obtidos, pode-se concluir que: 1) a produção e os teores de SST e ATT dos frutos da pereira-japonesa e da pinheira não foram influenciados pela aplicação foliar de B e de Zn; b) a mistura de ácido bórico com quelatos foi eficiente no fornecimento de B às plantas de pereira- japonesa, o mesmo não ocorrendo para pinheira, c) o sulfato de zinco + produtos quelatizantes foram eficientes no aumento dos teores foliares de Zn somente na pereira.

Termos para indexação: Pyrus pyrifolia, Annona Squamosa L., boro, zinco, quelatos.

\section{LEAF SPRAY FERTILIZATION OF BORON AND ZINC ON PRODUCTION, SST AND ATT IN FRUITS OF PEAR AND SUGAR APPLE}

\begin{abstract}
Leaf spray using liquid products with micronutrients, among them, quelates are usual in fruit trees. However, there is no research showing results on it. In this way, the aim of this study was to verify the effects of B and Zn applied on leaves on production, SST and ATT of pear fruit and sugar apple. The experiment was conducted on irrigated area in Ilha Solteira - SP, Brazil. A red brown Podzolic and plants of sugar apple and pear, Okussankichi cv. were used. The treatments were: T1. water, T2. boric acid, T3. zinc sulfate, T4. T2 + T3, T5 . boric acid + urea + citric acid + EDTA, T6. zinc sulfate + urea + citric acid + EDTA, T7. T5 + T6, T8. boric acid + urea + citric acid + EDTA + sodium molibdate + sulfur + calcium chloride, T9. zinc sulfate + citric acid + EDTA + Fe sulfate + Mn sulfate $+\mathrm{Mg}$ sulfate and, T10. T8 + T9. It was used doses of $110 \mathrm{~g} \mathrm{ha}^{-1}$ of B and $250 \mathrm{~g} \mathrm{ha}^{-1}$ of $\mathrm{Zn}$, in each application. A randomized blocks design was used and to compare the averages the Tukey test was applied. It can be concluded: a) the production, SST and ATT of pear fruits and sugar apple fruits were not influenced by B and Zn leaf application, b) boric acid plus quelates were efficient to supply B to pear plants but not to sugar apple plants, c) Zn sulfate plus quelates caused an increase in Zn leaf content only in pear plants.
\end{abstract}

Index Terms: Pyrus pyrifolia, Annona squamosa L., boron, zinc, quelates.

\section{INTRODUÇÃO}

Para diversas culturas perenes, a pulverização foliar com micronutrientes é uma rotina, aproveitando-se a aplicação de pesticidas (Abreu \& Raij, 1997). Vários fatores contribuíram para o interesse e uso da adubação foliar com micronutrientes, sendo as necessidades totais de algumas culturas freqüentemente atendidas com apenas uma aplicação (Lopes \& Souza, 2001).

Dentre os micronutrientes, o B e o Zn merecem especial atenção por se tratar de elementos cujas deficiências aparecem em maior freqüência nas culturas e por estarem diretamente relacionados à formação e à qualidade da colheita (Malavolta et al., 1997).

Comumente são utilizados sais, óxidos e quelatos como fontes de micronutrientes, e as recomendações de adubações com micronutrientes, quando indicadas nas tabelas de adubação, são para aplicações localizadas, em covas, ou mesmo na superfície do solo, para culturas perenes, exceto naqueles casos em que é prescrita a aplicação foliar. Nestes casos, podem ser utilizadas soluções de sais inorgânicos solúveis em água (Abreu \& Raij, 1997). Para os micronutrientes metálicos, as fontes mais recomendadas são sais formados com íons cloreto, sulfato e

\footnotetext{
${ }^{1}$ (Trabalho 129-06). Recebido em: 29-08-2006. Aceito para publicação em : 28-03-2007. Projeto com apoio financeiro da FAPESP (Fundação de Amparo à Pesquisa no Estado de São Paulo).

${ }^{2}$ Doutoranda do curso de pós-graduação da FEIS/UNESP/Campus de Ilha Solteira/SP. Email: eng_regina@yahoo.com.br.

3 Prof. Titular do depto de Fitossanidade, Engenharia Rural e Solos da FEIS/UNESP/Campus Ilha Solteira/SP. Bolsista em produtividade do CNPq. Email: sbuzetti@agr.feis.unesp.br
} 
nitrato, que têm praticamente a mesma eficiência, nas mesmas doses. Em aplicações foliares, a fonte de B mais recomendada é o ácido bórico, que, devido à reação ácida, é compatível com a maioria dos defensivos agrícolas (Quaggio \& Piza Junior, 2001).

De acordo com Hoffmann (2003), durante o período de floração da pereira, há um aumento na exigência de $\mathrm{B}$, o que pode causar deficiência do nutriente, mas aplicações com bórax na fase de botão rosado previnem esta deficiência e favorecem uma melhor fecundação dos óvulos. Para cultivares de pereiras sensíveis à deficiência de $\mathrm{B}$, como a 'Nijisseiki', desde que a análise foliar indique necessidade de aplicação foliar, fazem-se duas a três pulverizações quinzenais de bórax $0,4 \%$ ou solubor $0,2 \%$, a partir da queda das pétalas. Se o objetivo for usar o B como auxiliar na germinação do grão de pólen e na fecundação, as pulverizações iniciam-se com as flores no estádio balão (Basso \& Suzuki, 2001).

Para a cultura da pinha e anonáceas em geral, recomendase fazer uma análise do solo a cada 2 ou 3 anos, aplicando-se calcário dolomítico e cerca de 15 a $20 \mathrm{~g}$ de sulfato de zinco, se necessário (Spironello et al., 1998). De acordo com Kavati (1992), o fornecimento de micronutrientes via foliar para a cultura da atemóia (A. cherimolia Mill. x A. squamosa L.), principalmente $\mathrm{Zn}$ e B, resulta em respostas visuais, quanto ao desenvolvimento das plantas. Portanto, é interessante realizar duas aplicações anuais com estes micronutrientes via foliar, antes do florescimento e quando os frutos estão em desenvolvimento. Para esta aplicação, recomenda-se dissolver $250 \mathrm{~g}$ de sulfato de zinco e 50 $\mathrm{g}$ de ácido bórico em 100 litros de água.

Costa et al. (2002) observaram que aplicações de ácido bórico, tanto no solo quanto nas folhas, provocaram aumento na produtividade e no número de frutos da pinheira, assim como elevaram o vingamento dos frutos. Porém, as diferentes formas de aplicação não alteraram o peso médio, o comprimento e o diâmetro dos frutos.

Neste contexto, o objetivo deste trabalho foi verificar o efeito da aplicação via foliar de B e de Zn sobre a produção e os teores de SST e ATT dos frutos da Pereira-Japonesa e da Pinheira.

\section{MATERIAL E MÉTODOS}

O experimento foi conduzido no cinturão verde do município de Ilha Solteira-SP. O solo da área foi classificado como Podzólico Vermelho-Escuro, eutrófico, textura média/argilosa (Carvalho \& Mello, 1989). Nas Tabelas 1 e 2, são apresentados os resultados da análise do solo da área de Pereira Japonesa e de Pinheira, respectivamente, antes da instalação do experimento. O tipo climático da região é Aw, segundo a classificação de Köeppen, caracterizando-se como tropical úmido, com estação chuvosa no verão e seca no inverno. Sua precipitação média anual é de $1.300 \mathrm{~mm}$ e com temperatura média anual de $23,7^{\circ} \mathrm{C}$.

Foram utilizadas plantas de Pereira-Japonesa, cultivar Okussankichi, porta-enxerto de pereira comum, foi instalada no ano de 2001 e espaçamento $3 \mathrm{~m} \times 2 \mathrm{~m}$. As plantas foram conduzidas com duas pernadas e sem desbaste de frutos e mantidas sob irrigação. Para a adubação de produção, utilizara-se, em fevereiro, $180 \mathrm{~g} /$ planta da fórmula 10-10-10 e $9 \mathrm{~L} /$ planta de esterco bovino e, nos meses de abril, setembro e novembro, foram utilizados $40 \mathrm{~g} /$ planta de uréia.

A pinheira utilizada foi instalada no ano de 2001, através de sementes, em um espaçamento $4 \mathrm{~m}$ x $3 \mathrm{~m}$. As plantas foram conduzidas com 4 pernadas e sem desbaste de frutos e mantidas irrigadas, utilizando-se do sistema de gotejamento. Para a adubação de produção, foram aplicados $360 \mathrm{~g} /$ planta da fórmula 10-10-10 e $18 \mathrm{~L} /$ planta de esterco bovino e $80 \mathrm{~g} / \mathrm{planta}$ de uréia.

O delineamento experimental adotado foi o de blocos ao acaso, com quatro repetições, sendo cada parcela útil constituída por 3 plantas. Para comparação de médias, foi utilizado o teste de Tukey. Foram tomadas linhas intercaladas, assim como plantas intercaladas dentro da mesma linha, de tal modo que a planta a ser pulverizada estivesse isolada das outras que receberam pulverização.

Os tratamentos utilizados no experimento foram: T1. apenas água, T2. ácido bórico; T3. sulfato de zinco; T4. T2 + T3; T5. ácido bórico + uréia + ácido cítrico + EDTA; T6. sulfato de zinco + uréia + ácido cítrico + EDTA; T7. T5 + T6; T8. ácido bórico + uréia + ácido cítrico + EDTA + molibdato de sódio + enxofre + cloreto de cálcio; T9. sulfato de zinco + ácido cítrico + $\mathrm{EDTA}+$ sulfato de Fe + sulfato de $\mathrm{Mn}+$ sulfato de $\mathrm{Mg}$, e T10. T8+T9. Foram utilizadas doses de $110 \mathrm{~g} \mathrm{ha}^{-1} \mathrm{de} \mathrm{B}$ e $250 \mathrm{~g} \mathrm{ha}^{-1} \mathrm{de}$ $\mathrm{Zn}$ em cada aplicação. Foram realizadas pulverizações com intervalos de quinze dias cada. As pulverizações iniciaram no pleno florescimento das plantas, em 14 de setembro de 2004 para pinheira e em outubro de 2004 para a pereira e seguiram até a formação dos frutos, totalizando 3 e 4 pulverizações, respectivamente.

Por ocasião da colheita, foram avaliados: o número de frutos produzidos por planta, massa e produção total das plantas. Para a análise química das plantas, cerca de 20 dias após a última pulverização, foram coletadas por tratamento um total de 30 folhas recém-amadurecidas do crescimento do ano, ou totalmente expandidas, conforme recomendado por Raij \& Piza Junior (1997). As folhas foram secas em estufa com circulação forçada de ar a $65^{\circ} \mathrm{C}+/-2^{\circ} \mathrm{C}$ até massa em equilíbrio, conforme metodologia recomendada por Malavolta et al. (1997). No laboratório, separaram-se 10 frutos por tratamento e, em seguida, foram realizadas as avaliações dos teores de SST e ATT utilizando as normas estabelecidas pelo Instituto Adolfo Lutz (1985).

\section{RESULTADOS E DISCUSSÃO}

Observou-se para os teores de B em pereira (Tabela 3), que o tratamento contendo ácido bórico + uréia + ácido cítrico + EDTA + molibdato de sódio + enxofre + cloreto de cálcio foi significativamente superior à testemunha (apenas água). Os outros tratamentos contendo B não diferiram entre si. Para o Zn, Tabela 3, todos os tratamentos contendo $\mathrm{Zn}$ mais quelatos diferiram da testemunha. $\mathrm{O} Z \mathrm{Zn}$ como sulfato não diferiu tanto da testemunha como dos tratamentos contendo EDTA.

$\mathrm{Na}$ Tabela 4, observa-se que os teores de B e $\mathrm{Zn}$ em pinheira não diferiram estatisticamente entre si, assim como não diferiram da testemunha (apenas água). Santos et al. (1999), comparando a eficiência de formulações de adubos foliares 
quelatizados na absorção dos micronutrientes B, Mn e Zn, com a aplicação convencional de sais em plantas de laranja 'Pêra' (Citrus sinensis (L.) Osbeck), observaram aumento do teor foliar de Mn e Zn, mas não de B.

Para a pereira (Tabela 3) e pinheira (Tabela 4), tanto a aplicação de ácido bórico, como de sulfato de zinco, com ou sem outros produtos não influenciaram no número médio de frutos por planta, a massa média dos frutos, a produção por planta, os SST e a ATT. Resultados semelhantes foram observados por Tiritan (1996), na comparação da mistura dos micronutrientes $\mathrm{Zn}, \mathrm{Mn}$ e B com várias outras misturas de adubos foliares encontradas no comércio, dentre os quais produtos quelatizados. Observou-se que a aplicação foliar em cítrus foi suficiente para elevar os teores foliares desses nutrientes, contudo não houve aumento na produção, massa média dos frutos, porcentagem de suco, SST, ATT e ratio. Entretanto, Usha \& Singh (2002) obtiveram resultado positivo na produção e qualidade de frutos de videira, cultivar Perlette, com a aplicação foliar de B, Zn, Fe e Mn, bem como Stover et al. (1999) na produção de maçã cultivar McIntosh, com aplicação foliar de B, na forma de solubor e Zn, na forma de quelato de zinco.

Aplicações foliares de bórax foram eficientes para elevar os teores de B nas folhas das plantas de abacaxi, de acordo com Siebeneichler et al. (2002), contudo não foi suficiente para alterar a massa do fruto e as características físicas e químicas, com exceção do conteúdo de SST que sofreu ligeiro aumento.

Basso \& Suzuki (2001), para pomares de pereira-japonesa em Santa Catarina, consideram normais os teores de B entre 25 a $50 \mathrm{mg} / \mathrm{kg}$; e para um bom estado nutricional, as plantas devem ter entre 20 a $100 \mathrm{mg} / \mathrm{kg}$. De acordo com os mesmos autores, teores de $\mathrm{Zn}$ acima do normal a excessivo, devido a aplicações foliares de sais ou fungicidas, não constituem toxidez, devendo ser considerados na interpretação dos resultados. No Japão, são considerados teores normais para as cultivares Kousui e Housui teores de B entre 30 a 90 mg/kg e Zn entre 50 a 90 mg/kg.

Em ateiras/pinheiras cultivadas no Nordeste, os teores foliares de $107 \mathrm{mg} / \mathrm{kg}$ de B foram observados por Kist \& Manica (1994) e 44,6 a 87,6mg/kg de B verificados por Carvalho \& Nogueira (2002) na composição mineral da cultura da pinha cultivada no Estado do Rio de Janeiro. Para o Zn, foram observados $20 \mathrm{mg} / \mathrm{kg}$ de Zn por Kist \& Manica (1994) e 12,7 a 29,1 mg/kg de Zn verificados por Carvalho \& Nogueira (2002).
Considerando que os teores de B e $\mathrm{Zn}$ se aproximam dos teores relatados para essas culturas, nas diferentes regiões do País, e que não foi observada nenhuma deficiência nutricional, pode-se considerar que as plantas apresentavam bom estado nutricional mesmo na ausência de adubação foliar, resultado que pode ser atribuído à aplicação anual de esterco bovino utilizado na adubação de produção conforme as recomendações técnicas para essas culturas. Esse procedimento pode ter contribuído para a manutenção da fertilidade do solo, onde se verifica que os teores de B e Zn no solo (Tabelas 1 e 2) se encontram dentro dos níveis médio e alto, respectivamente. De acordo com Basso \& Suzuki (2001), em solos, bem providos de matéria orgânica e com $\mathrm{pH}$ inferior a 7 , normalmente não há problemas com a falta de B.

Neste trabalho, verificou-se que as aplicações foliares de $\mathrm{B}$ e de $\mathrm{Zn}$ elevaram os teores destes nutrientes em pereira, não ocorrendo em pinheira. Porém, esse aumento no teor foliar não foi suficiente para induzir uma resposta das plantas ao aumento da produção ou alteração dos SST e ATT dos frutos. Caetano (1982) também não encontrou efeito na produção de plantas cítricas através do fornecimento de micronutrientes via foliar em pomares aparentemente nutridos e equilibrados.

Em macieiras, cítrus e videiras, um pré-requisito essencial para respostas das plantas à aplicação foliar de $\mathrm{Zn}$ parece ser a presença de sintomas de deficiência de $\mathrm{Zn}$, de acordo com Swietlik (2002), o que não ocorreu no presente trabalho. Por outro lado, o manejo da adubação com boro em plantas é diretamente influenciado pelos padrões de mobilidade de B.

Evidências experimentais demonstram claramente que o B aplicado via foliar pode ser translocado para órgãos em crescimento nas espécies com significante mobilidade desse nutriente no floema, espécies tais que produzem açúcares simples, como o manitol, o sorbitol e o dulcitol. Os resultados obtidos por Brown \& Hu (1998) demonstraram benefícios significativos da aplicação foliar desse nutriente na frutificação de muitas espécies frutíferas como consequência desta mobilidade.

Entretanto, no presente trabalho, provavelmente a ausência de efeito significativo para o B se deve ao teor adequado no solo e às aplicações de esterco bovino realizadas na cultura. Tal prática é comum para estas fruteiras e, mesmo assim, são realizadas pulverizações foliares com macro e micronutrientes.

TABELA 1 - Análise química do solo da área de pinheira antes da aplicação dos tratamentos. Ilha Solteira - SP.

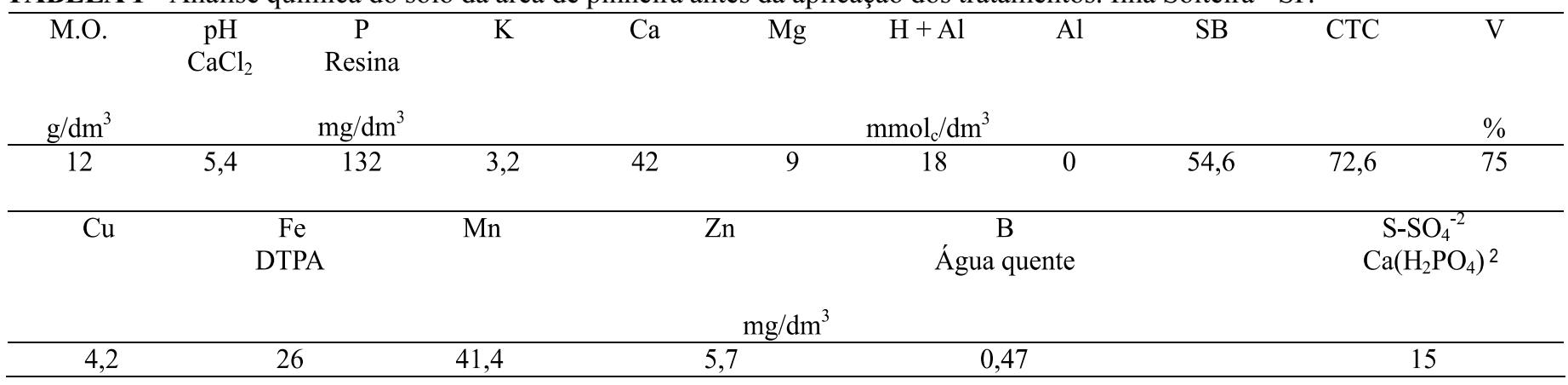


TABELA 2 - Análise química do solo da área de pereira-japonesa antes da aplicação dos tratamentos. Ilha Solteira- SP.

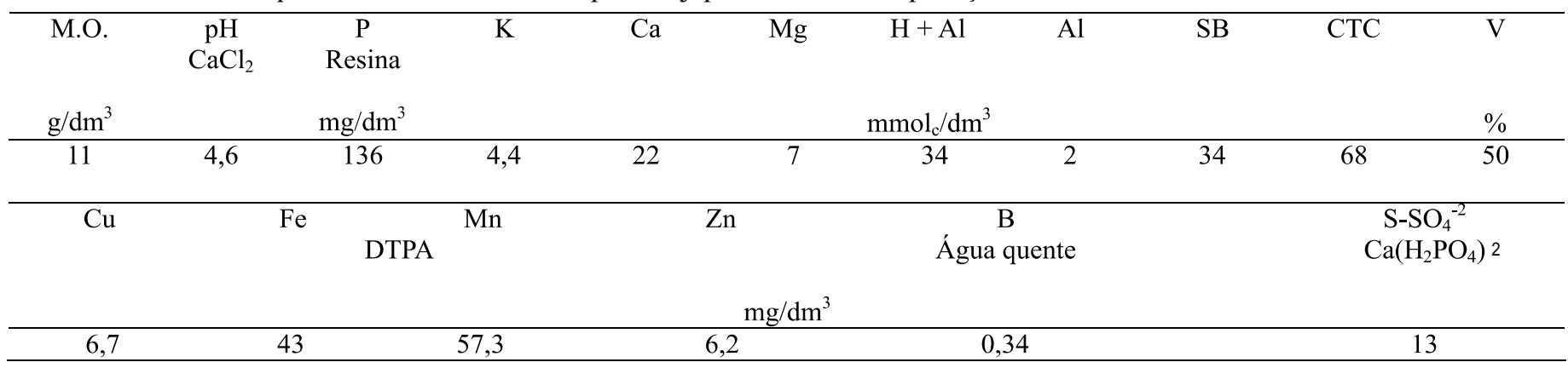

TABELA 3 - Teores médios de boro e zinco, produção e SST, ATT dos frutos de Pereira-Japonesa submetida à adubação foliar, colheita 25-01-05 a 14-02-05. Ilha Solteira-SP.

\begin{tabular}{|c|c|c|c|c|c|c|c|}
\hline Tratamentos & $\begin{array}{c}\text { Boro } \\
(\mathrm{mg} / \mathrm{kg})\end{array}$ & $\begin{array}{c}\text { Zinco } \\
(\mathrm{mg} / \mathrm{kg})\end{array}$ & $\begin{array}{l}\text { Número } \\
\text { médio de } \\
\text { frutos/pl }\end{array}$ & $\begin{array}{l}\text { Massa } \\
\text { média de } \\
\text { frutos } \\
\text { (g) }\end{array}$ & $\begin{array}{l}\text { Produção } \\
\text { (g/planta) }\end{array}$ & $\begin{array}{l}\text { Sólidos } \\
\text { solúveis } \\
\text { totais } \\
\left({ }^{\circ} \text { Brix) }\right.\end{array}$ & $\begin{array}{l}\text { Acidez total } \\
\text { titulável } \\
\text { (g de ácido } \\
\text { cítrico/100g } \\
\text { de polpa) }\end{array}$ \\
\hline 1. Apenas água & $85,5 b^{*}$ & $44,5 b^{*}$ & $44,00 a^{*}$ & $187,00 a^{*}$ & $7761 a^{*}$ & $10,00 a^{*}$ & $0,145 a^{*}$ \\
\hline 2. Ácido bórico & $132,0 \mathrm{ab}$ & $40,0 b$ & $45,00 \mathrm{a}$ & $203,00 \mathrm{a}$ & $6587 \mathrm{a}$ & $10,00 \mathrm{a}$ & $0,133 a$ \\
\hline 3. Sulfato de zinco & $90,5 b$ & $165,5 \mathrm{ab}$ & $62,00 \mathrm{a}$ & $222,00 a$ & $11113 \mathrm{a}$ & $10,00 \mathrm{a}$ & $0,155 \mathrm{a}$ \\
\hline 4. Trat $2+$ Trat 3 & $129,5 \mathrm{ab}$ & $165,0 \mathrm{ab}$ & $54,00 \mathrm{a}$ & $214,50 \mathrm{a}$ & $10769 \mathrm{a}$ & $10,50 \mathrm{a}$ & $0,145 \mathrm{a}$ \\
\hline 5. Ácido bórico + uréia + ácido cítrico + EDTA & $136,0 \mathrm{ab}$ & $40,0 \mathrm{~b}$ & $31,50 \mathrm{a}$ & $222,00 a$ & $7840 \mathrm{a}$ & $10,00 \mathrm{a}$ & $0,216 \mathrm{a}$ \\
\hline 6. Sulfato de zinco + uréia + ácido cítrico + EDTA & $98,0 \mathrm{ab}$ & $198,0 \mathrm{a}$ & $40,00 \mathrm{a}$ & $216,00 \mathrm{a}$ & $6055 \mathrm{a}$ & $10,00 \mathrm{a}$ & $0,143 \mathrm{a}$ \\
\hline 7. Trat $5+$ Trat 6 & $100,0 \mathrm{ab}$ & $184,0 \mathrm{a}$ & $48,00 \mathrm{a}$ & $228,00 a$ & $9469 \mathrm{a}$ & $11,00 \mathrm{a}$ & $0,257 \mathrm{a}$ \\
\hline $\begin{array}{l}\text { 8. Ácido bórico }+ \text { uréia }+ \text { ácido cítrico }+ \text { EDTA }+ \\
\text { molibdato de sódio }+ \text { enxofre }+ \text { cloreto de cálcio }\end{array}$ & $172,5 \mathrm{a}$ & $36,5 b$ & $36,50 a$ & $254,00 a$ & $7462 \mathrm{a}$ & $10,00 \mathrm{a}$ & $0,225 \mathrm{a}$ \\
\hline $\begin{array}{l}\text { 9. Sulfato de zinco }+ \text { ácido cítrico }+ \text { EDTA }+ \\
\text { sulfato de } \mathrm{Fe}+\text { sulfato de } \mathrm{Mn}+\text { sulfato de } \mathrm{Mg}\end{array}$ & $88,0 \mathrm{~b}$ & $184,5 \mathrm{a}$ & $53,00 \mathrm{a}$ & $184,00 \mathrm{a}$ & $6445 a$ & $10,00 \mathrm{a}$ & $0,125 \mathrm{a}$ \\
\hline 10. Trat $8+$ Trat 9 & $105,5 \mathrm{ab}$ & $207,5 \mathrm{a}$ & $42,00 \mathrm{a}$ & $216,00 \mathrm{a}$ & $6151 \mathrm{a}$ & $10,50 \mathrm{a}$ & $0,143 \mathrm{a}$ \\
\hline C.V. $(\%)$ & 16,97 & 27,14 & 35,56 & 27,43 & 29,51 & 5,66 & 24,42 \\
\hline
\end{tabular}

*médias seguidas por letras minúsculas iguais na coluna não diferem entre si, pelo teste de Tukey, ao nível de $5 \%$ de probabilidade.

TABELA 4 - Teores médios de boro e zinco, produção e SST, ATT dos frutos da pinheira submetida à adubação foliar, colheita 16-1204 a 04-01-05. Ilha Solteira-SP.

\begin{tabular}{|c|c|c|c|c|c|c|c|}
\hline Tratamentos & $\begin{array}{c}\text { Boro } \\
(\mathrm{mg} / \mathrm{kg})\end{array}$ & $\begin{array}{l}\text { Zinco } \\
(\mathrm{mg} / \mathrm{kg})\end{array}$ & $\begin{array}{l}\text { Número } \\
\text { médio de } \\
\text { frutos/pl }\end{array}$ & $\begin{array}{l}\text { Massa } \\
\text { média de } \\
\text { frutos } \\
(\mathrm{g})\end{array}$ & $\begin{array}{l}\text { Produção } \\
\text { (g/planta) }\end{array}$ & $\begin{array}{l}\text { Sólidos } \\
\text { solúveis } \\
\text { totais } \\
\left({ }^{\circ} \text { Brix) }\right.\end{array}$ & $\begin{array}{l}\text { Acidez total } \\
\text { titulável } \\
\text { (g de ácido } \\
\text { cítrico/100g } \\
\text { de polpa) }\end{array}$ \\
\hline 1.Apenas água & $42,5 a^{*}$ & $16,5 a^{*}$ & $19,49 a^{*}$ & $281,50 a^{*}$ & $5425 a^{*}$ & $23,50 a^{*}$ & $0,340 a^{*}$ \\
\hline 2.Ácido bórico & $42,0 \mathrm{a}$ & $16,5 \mathrm{a}$ & $34,58 \mathrm{a}$ & $268,00 a$ & $5922 \mathrm{a}$ & $23,00 a$ & $0,375 \mathrm{a}$ \\
\hline 3.Sulfato de zinco & $49,0 \mathrm{a}$ & $26,0 \mathrm{a}$ & $19,18 \mathrm{a}$ & $310,00 a$ & $5269 a$ & $24,50 \mathrm{a}$ & $0,400 \mathrm{a}$ \\
\hline 4. Trat $2+$ Trat 3 & $44,5 \mathrm{a}$ & $28,0 \mathrm{a}$ & $22,51 \mathrm{a}$ & $288,00 a$ & $3969 a$ & $23,00 \mathrm{a}$ & $0,395 \mathrm{a}$ \\
\hline 5.Ácido bórico + uréia + ácido cítrico + EDTA & $91,5 \mathrm{a}$ & $22,0 \mathrm{a}$ & $39,80 \mathrm{a}$ & $246,00 a$ & $6197 a$ & $22,50 a$ & $0,370 \mathrm{a}$ \\
\hline $\begin{array}{l}\text { 6.Sulfato de zinco + uréia + ácido cítrico + } \\
\text { EDTA }\end{array}$ & $58,0 \mathrm{a}$ & $27,5 \mathrm{a}$ & $28,88 \mathrm{a}$ & $310,50 a$ & $6010 a$ & $24,00 \mathrm{a}$ & $0,370 \mathrm{a}$ \\
\hline 7. Trat $5+$ Trat 6 & $79,0 \mathrm{a}$ & $24,0 \mathrm{a}$ & $17,94 \mathrm{a}$ & $266,50 a$ & $5434 a$ & $22,50 \mathrm{a}$ & $0,335 a$ \\
\hline $\begin{array}{l}\text { 8. Ácido bórico }+ \text { uréia }+ \text { ácido cítrico }+ \text { EDTA }+ \\
\text { molibdato de sódio }+ \text { enxofre }+ \text { cloreto de cálcio }\end{array}$ & $61,0 \mathrm{a}$ & $18,5 \mathrm{a}$ & $45,36 a$ & $270,50 a$ & $7140 a$ & $25,00 \mathrm{a}$ & $0,370 \mathrm{a}$ \\
\hline $\begin{array}{l}\text { 9.Sulfato de zinco + ácido cítrico + EDTA + } \\
\text { sulfato de } \mathrm{Fe}+\text { sulfato de } \mathrm{Mn}+\text { sulfato de } \mathrm{Mg}\end{array}$ & $38,0 \mathrm{a}$ & $24,0 \mathrm{a}$ & $30,22 \mathrm{a}$ & $310,50 \mathrm{a}$ & $5072 \mathrm{a}$ & $23,00 \mathrm{a}$ & $0,380 a$ \\
\hline 10. Trat $8+$ Trat 9 & $64,5 \mathrm{a}$ & $25,5 \mathrm{a}$ & $28,88 \mathrm{a}$ & $262,50 a$ & $5619 a$ & $24,00 a$ & $0,425 a$ \\
\hline C.V.\% & 27,09 & 14,44 & 37,49 & 13,42 & 38,57 & 4,87 & 12,94 \\
\hline
\end{tabular}

*médias seguidas por letras minúsculas iguais na coluna não diferem entre si, pelo teste de Tukey, ao nível de 5\% de probabilidade.

\section{CONCLUSÃO}

Com base nos resultados obtidos, pode-se concluir que:

A produção e os teores de SST e ATT dos frutos da pereira-japonesa e da pinheira não foram influenciados pela aplicação foliar de B e de Zn; b) a mistura de ácido bórico com quelatos foi eficiente no fornecimento de $\mathrm{B}$ às plantas de pereirajaponesa, o mesmo não ocorrendo para pinheira; c) o sulfato de zinco + produtos quelatizantes foram eficientes no aumento dos teores foliares de $\mathrm{Zn}$ somente na pereira. 


\section{REFERÊNCIAS}

ABREU, C.A.; RAIJ, B. van. Adubação com micronutrientes. In: RAIJ, B. Van; CANTARELLA, H.; QUAGGIO, J.A.; FURLANI, A.M.C. Recomendações de adubação e calagem para o Estado de São Paulo. 2.ed. Campinas: Instituto Agronômico, 1997. p.29 (Boletim técnico, 100).

BASSO, C.; SUZUKI, A. Solos e nutrição. In: EPAGRI. Nashi: a pêra-japonesa. Florianópolis: EPAGRI/JICA, 2001. p.139-160.

BROWN, P.; HU, H. Manejo do boro de acordo com sua mobilidade nas diferentes culturas. Informações agronômicas, Piracicaba, n.84, p.1-4, 1998.

CAETANO, A.A. Estudo da eficiência de várias fontes dos micronutrientes, zinco, manganês e boro aplicados em pulverizações na laranjeira 'Valência' (Citrus sinensis (L.) Osbeck). 1982, 46f. Dissertação (Mestrado em Agronomia)Escola Superior de Agricultura "Luiz de Queiroz", Universidade de São Paulo, Piracicaba, 1982.

CARVALHO, M.P.; MELLO, L.M. Classificação da capacidade de uso da terra do antigo pomar da Fazenda de Ensino e Pesquisa da Faculdade de Engenharia de Ilha Solteira-FEIS/ UNESP. Ilha Solteira: UNESP/FEIS, 1989.46p.

CARVALHO, A.J.C.; NOGUEIRA, A.S. Teores de micronutrientes na cultura da pinha (Annona squamosa L.) em função de épocas de poda de produção, amostragem foliar e métodos de polinização no norte do Estado do Rio de Janeiro. In: CONGRESSO BRASILEIRODE FRUTICULTURA, 27., 2002, Belém/PA. Anais... Belém: SBF/EMBRAPA, 2002. CD-ROM.

COSTA, S.L.; CARVAlHO, A.J.; PESSANHA, P.G.O.; MONNERAT, P.H.; MARINHO, C.S. Produtividade da cultura da Pinha (Annona squamosa L.) em função de níveis de adubação nitrogenada e formas de aplicação de boro. Revista Brasileira de Fruticultura, Jaboticabal, v.24, n.2, p.543-546, 2002.

HOFFMANN, A. Pereira. In: CASTRO, P.R.C.; KLUGE, R.A. Ecofisiologia de fruteiras: abacateiro, aceroleira, macieira, pereira e videira. Piracicaba: Ceres, 2003. p. 65-92.

INSTITUTO ADOLFO LUTZ. Normas analíticas, métodos químicos e físicos para análises de alimentos. 3. ed. São Paulo: ITAL, 1985. v.1, 533p.

KAVATI, R. Instruções para a cultura da atemóia. Campinas: CATI, 1992.5p. (Comunicado técnico, 88).

LOPES, A.S.; SOUZA, E.C.A. Filosofias e eficiência da aplicação. In: FERREIRA, M.E. et al. (Eds.). Micronutrientes e elementos tóxicos na agricultura. Jaboticabal: CNPq, FAPESP/PATAFOS, 2001.p. 268.

MALAVOLTA, E.; VITTI, G.C.; OLIVEIRA, S.A. Avaliação do estado nutricional das plantas: princípios e aplicações. Piracicaba: Associação Brasileira para pesquisa da Potassa e do Fosfato, 1997. 319P.

KIST, H.G.K.; MANICA, I. Adubação e irrigação. In: MANICA, I. Fruticultura: cultivo de anonáceas ata-cherimólia-graviola. Porto Alegre: EVANGRAF, 1994. p.53.

QUAGGIO, J.A.; PIZA JUNIOR, C.T. Fruteiras Tropicais. In: FERREIRA, M.E. et. al. (Eds.) Micronutrientes e elementos tóxicos na agricultura. Jaboticabal: CNPq, FAPESP/
POTAFOS, 2001. p. 459-492.

RAIJ, B. Van.; PIZA JUNIOR, C.T. Frutíferas. In: RAIJ, B. Van; CANTARELLA, H.; QUAGGIO, J.A.; FURLANI, A.M.C. Recomendações de adubação e calagem para o Estado de São Paulo. 2.ed. Campinas: Instituto Agronômico, 1997.p.123 (Boletim técnico 100).

SANTOS, C.H.; DUARTE FILHO, J.; MODESTO, J.C.; GRASSI FILHO, H. \& FERREIRA, G. Adubos foliares quelatizados e sais na absorção de boro, manganês e zinco em laranjeira 'Pêra'. Scientia Agricola, Piracicaba, v.56, n.4, p.999-1004, 1999.

SIEBENEICHLER, S.C.; MONNERAT, P.H.; CARVALHO, A.J.C.; VIEIRA, A.; SILVA, J.A. Efeito de boro foliar na cultura do Abacaxi no Noroeste Fluminense. In: CONGRESSO BRASILEIRO DE FRUTICULTURA, 27., 2002, Belém/PA. Anais... Belém: SBF/EMBRAPA, 2002. CD-ROM.

SPIRONELLO, A.; SOARES, N.B.; KAVATI, R. Anona, In: FAHL. J.I. et al. (Eds.). Instruções agrícolas para principais culturas econômicas. Campinas: Instituto Agronômico, 1998. p.101. (Boletim técnico, 200)

STOVER, E.; FARGIONE, M.; RISIO, R.; STILES, W.; IUNGERMAN,K. Prebloom foliar boron, zinc, and urea applications enhance cropping of some 'Empire' and "McIntosh" apple orchards in New York. HortScience, Alexandria, v.34, n.2, 1999. Disponível em: <www.ashs.org/ hortscience>. Acesso em: 18 fev. 2006.

SWIETLIK, D. Zinc Nutrition of fruit trees by foliar sprays. Acta Horticulturae, Wageningen, v.1, n.594, p.123-129, 2002.

TIRITAN, S.T. Adubação foliar de micronutrientes em citros. 1996. 64f. Dissertação (Mestrado em Agronomia) - Escola Superior de Agricultura “Luiz de Queiroz", Universidade de São Paulo, Piracicaba, 1996.

USHA, K.; SINGH, B. Effect of macro and micro-nutrient spray on fruit yield and quality of grape (Vitis vinifera L.) cv. Perlette. Acta Horticulturae, Wageningen, v.1, n.594, p.197202, 2002. 